\section{Similarities between memory for visually perceived relations and comparative sentences*}

\author{
JOHN BENJAFIELD and BRIAN DOAN \\ Brock University, St. Catharines, Ont., Canada
}

\begin{abstract}
"Positive" comparative sentences (e.g., "A is larger than B") are more easily remembered than their opposites (e.g., "A is smaller than B"). Memory for the visually perceived relations denoted by both kinds of comparative sentences was investigated using standard paired-associate techniques. A test of aided recall revealed that the ease with which these relations are remembered is similar to the ease with which their corresponding descriptions are remembered. This result indicates that comparative sentences and visually perceived transitive asymmetrical relations are encoded in memory in the same way.
\end{abstract}

Clark \& Card (1969) have recently shown that some comparative sentences are more easily remembered than others. Sentences making "positive" comparisons (e.g., "A is better than $B$ ") are usually recalled more accurately than sentences which make "negative" comparisons (e.g., "A is worse than B"). Clark $(1969,1970$; Clark \& Card, 1969) explains this finding by positing that the positive adjective of an antonymous adjective pair can be stored in memory in a simpler form than its negative opposite. This is because the former is "unmarked" (Greenberg, 1966; Marshall, 1968)-it can have not only a contrastive, but also a nominal sense. The latter type of adjective can have only a contrastive sense-that is, it is "marked." "Good" is the name of the good-bad dimension. "Bad" is a pole on that dimension. Thus, "good" can be retained in memory without specifying the pole of the dimension. "Bad" can only be stored with such a specification. Therefore, the memory code for unmarked adjectives is simpler than that for marked adjectives, and the former is easier to retrieve.

This reasoning can be applied by analogy to gain an understanding of memory for visually perceived asymmetrical transitive relations. The relations to be considered have two terms, $A$ and $B$, arranged so that $A$ is always to the left of $B$. The relation labeled Type I in Fig. 1 can be described either by the statement "A is fuller than B" or by the statement " $B$ is emptier than A." The former contains an unmarked adjective, the latter a marked adjective. In this paper, Type I relations are defined as those whose description is either " $\mathrm{A}$ is (unmarked adjective) than $B$ " or " $B$ is (marked adjective) than A." The

*This work was supported by a National Research Council of Canada grant (No. APA-7652) to the first author. relation labeled Type II in Fig. 1 was constructed by reversing the position of the A and B members of the Type I relation. In general, Type II relations are defined as those whose descriptions are " $\mathrm{A}$ is (marked adjective) than $B$ " and "B is (unmarked adjective) than A."

Memory for these two types of relations can be investigated using standard paired-associate techniques. If memory for these visually perceived relations is similar to memory for their corresponding comparative sentences, then Type I relations should be easier to remember than Type II relations in a test of forward aided recall. The reason for this is that if $S$ relates $A$ to $B$ during learning, then he must recall an "unmarked" relation in the Type I case (e.g., "A is fuller than B"). However, telling $S$ to expect a test of backward aided recall after learning should increase the likelihood of $\mathbf{S}$ relating $B$ to $A$ during learning. In that case, Type II relations would be "unmarked" and Type I relations "marked," and therefore Type II relations easier to recall than Type I relations. It follows that Type I

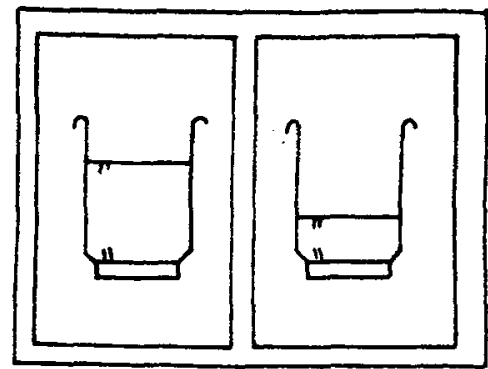

A B

TYPE I relations will be easier to recall in forward rather than backward aided recall, and Type II relations easier to recall in backward rather than forward aided recall.

\section{MATERIALS}

One list of Type I and one list of Type II relations were constructed. The relations were depicted by drawings of familiar objects [e.g., one pencil with a sharper point than the other; two cross sections of a beach, one where the water drops off more rapidly (is deeper) than the other]. Each relation was drawn in black ink on an $11 \times 8 \frac{1}{2}$ in. white card, with a $4 \frac{1}{2} \times 7 \frac{114}{4}$ in. border drawn around both the $A$ and $B$ terms (see Fig. 1). The Type I list contained the following relations between $A$ and $B$ : (1) straighter, (2) sharper, (3) fuller, (4) more, (5) farther, (6) deeper, (7) thicker, (8) longer, (9) bigger, (10) higher. The Type II list was constructed by simply reversing the $A$ and $B$ members of the first list to yield the following opposite relations between $A$ and B: (1) crookeder, (2) duller, (3) emptier, (4) less, (5) nearer, (6) shallower, (7) thinner, (8) shorter, (9) smaller, (10) lower. Experimental Design and Procedure

A 2 by 2 design was used where $S$ was shown either the Type I or the Type II list, and either instructed to expect a test of forward or instructed to expect a test of backward recall after learning. The E told all Ss "I am going to show you a set of cards. Each card has a form on the left paired with a different form on the right. Later on I will show you the form on the left (right) and ask you to draw the form on the right (left)." The cards were presented in a different random order to each S. Each card was shown for 3 sec, with no insterstimulus interval. After. $S$ had seen the cards once, he did multiplication problems for $3 \mathrm{~min}$. $\mathrm{He}$

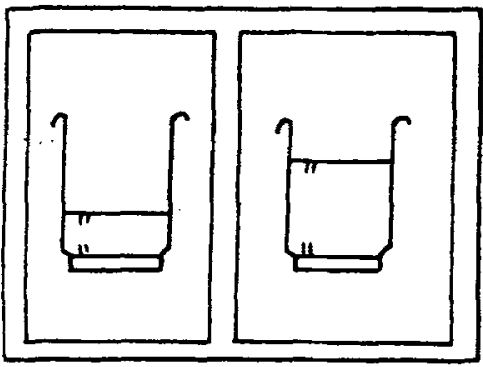


Table 1

Learning and Recall Data

\begin{tabular}{cccccc}
$\begin{array}{c}\text { Type of } \\
\text { Recall }\end{array}$ & $\begin{array}{c}\text { Type of } \\
\text { Relation }\end{array}$ & $\begin{array}{c}\text { Median } \\
\text { Correct } \\
\text { Items }\end{array}$ & Range & $\begin{array}{c}\text { GM Times } \\
\text { to Recall } \\
\text { (Seconds) }\end{array}$ & SD \\
\hline \multirow{2}{*}{ Forward } & I & 9 & $8-10$ & 12.0 & 2.4 \\
Backward & II & 8 & $5-10$ & 20.1 & 2.5 \\
\end{tabular}

was then given a booklet containing alternating blank and test pages. Each test page was a replica of one of the relational cards, with either the $B$ figure missing (for forward recall) or the A figure missing (for backward recall). The $S$ was instructed to draw the missing figure. The time to recall for each item was measured from the time $\mathrm{S}$ turned a blank page until he finished drawing and turned the test page. No time limit was placed on $S$, except that when he said that he could not recall an item he was told to go on to the next item.

The Ss were 60 undergraduate student volunteers at Brock University. Fifteen Ss were assigned randomly to each of the four treatment conditions.

$$
\text { RESULTS }
$$

Because of inhomogeneity of variance and skewed distributions, the learning data were analyzed nonparametrically. As shown in Table 1, learning was quite high in all groups, with no significant differences between them (median test, $x^{2}=3.54$, $\mathrm{df}=3, \mathrm{p}>.30)$.

Since the focus of the study was on ease of correct recall, the data for incorrectly recalled items was removed. Table 1 shows that the groups differed in the predicted directions in their geometric mean times to correct recall. There were significant effects of type of relation $[F(1,56)=8.57, p<.01]$ and type of recall $[F(1,56)=4.86, p<.05)$ and $a$ $\mathrm{signif}$ icant interaction $[F(1,56)=29.42, \quad p<.001]$. (The analysis was performed on the mean $\log$ times to recall for each S.)

Comparison of the differences between means by the Newman-Keuls method showed the only nonsignificant difference to be between the groups given Type I relations in forward and Type II relations in backward recall. In forward recall, Type I relations were recalled faster than Type II relations $(\mathrm{p}<.01)$, and vice versa in backward recall $(\mathrm{p}<.05)$. As predicted, forward was superior to backward recall for Type I relations $(p<.05)$, and vice versa for Type II relations $(p<.01)$ The only significant nonpredicted difference was that between Type II relations in forward and Type I relations in backward recall $(p<.01)$.

With forward recall, $t$ tests revealed that the following nine Type I relations were recalled significantly faster than their Type II counterparts: No. $2(\mathrm{p}<.01)$; No. $3(\mathrm{p}<.01) ;$ No. 4 $(\mathrm{p}<.001) ;$ No. $5 \quad(\mathrm{p}<.001) ;$ No. 6 $(\mathrm{p}<.05) ; \quad$ No. $7 \quad(\mathrm{p}<.01) ;$ No. 8 $(\mathrm{p}<.001) ;$ No. $9 \quad(\mathrm{p}<.05) ;$ and No. $10 \quad(\mathrm{p}<.01)$. With backward recall, t tests revealed that the recalled significantly faster than the corresponding Type I relations: No. 1 $(\mathrm{p}<.001) ;$ No. $2 \quad(\mathrm{p}<.01) ;$ No. 3 (p<.05, one-tailed); No. $5(\mathrm{p}<.05)$; No. $7(p<.01)$; and No. $9(p<.05$, one-tailed). No other differences were significant.

\section{DISCUSSION}

The difference between Type II in forward recall and Type I relations in backward recall may be due to $S s$ in the latter condition adopting a mixed strategy of constructing some relations in the forward and some in the backward direction. This would account for the performance of Type I backward Ss falling between that of Ss in Type I forward and that of Ss in Type II forward, since some of their relations would be "marked" some "unmarked." The Ss in the Type II backward condition would not tend to construct relations in the forward direction, since constructing in the following six Type II relations were backward direction yields the simpler " u n m a r k ed, relat i on. Postexperimental interviews tended to verify these interpretations.

In general, the experiment bears out the posited similarity between the way visually perceived transitive asymmetrical relations and comparative sentences are remembered. There is no reason why such relations and their corresponding descriptions could not be encoded in the same way in memory. Some common phenomena testify to the possibility that the same memory code underlies both kinds of event. Thus, one can see a relation and later describe it from memory or, conversely, hear a description of a relation and later imagine the situation to which the description referred. Obviously, the processes for constructing a memory image from a memory code would be quite different from the processes for constructing a descriptive sentence from that code.

Clark's (1969) theory can be seen as a theory of response availability (Asch \& Ebenholtz, 1962; Horowitz, Norman, \& Day, 1966). Responses differing in availability differ in the ease with which they can be recalled. The kind of theory Clark (1969) has developed can be used to account for the differential availability of visually perceived transitive asymmetrical relations.

\section{REFERENCES}

ASCH, S., \& EBENHOLTZ, S. The principle of associative symmetry. Proceedings of the American Philosophical Society, $1962,106,135-163$.

CLARK. H. H. Linguistic processes in deductive reasoning. Psychological Review, 1969, 76, 387-404.

CLARK, H. H. The primitive nature of children's relational concepts. In J. R. Hayes (Ed.), Cognition and the development of language. $\mathrm{New}$ York: Wiley, 1970 .

CLARK, H. H., \& CARD, S, K. The role of semantics in remembering comparative sentences. Journal of Experimental Psychology, 1969, 82, 545-553.

GREENBERG, J. H. Language universals. The Hague: Mouton, 1966.

HOROWITZ, L. M. NORMAN, S. A., \& DAY, R. S. Availability and associative symmetry. Psychological Review, 1966 , 73, 1-15.

MARSHALL, J. Psychological aspects of semantic structure. In R. Meetham (Ed.), Encyclopedia of linguistics information and control, London: Pergamon, 1968. 